Tecinologia educacional:

O trabalho trata do desenvolvimento de software educativo para o ensino do tema Escala de Pessoal de Enfermagem. $\mathrm{O}$ desenvolvimento do hipertexto, implementado via Internet, teve como objetivo oferecer subsídios para o aluno de graduação e para o enfermeiro gerente de recursos humanos. Aborda aspectos trabalhistas, legais e humanos fundamentais para o profissional enfermeiro.

Etapas metodológicas: revisão bibliográfica; organização da rede semântica; organização do hipertexto a partir dos nós de conteúdo; definição do design das telas e imagens; elaboração da simulação; planejamento do banco de dados.

Coleta de dados: por meio de formulário eletrônico no próprio site, preenchido por docentes de Administração em Enfermagem e alunos de graduação das escolas públicas de Enfermagem do Estado de São Paulo convidados.

Principais resultados: o site recebeu aprovação da maioria dos participantes. A média de aprovação, somando os critérios excelente e satisfatório, foi de $70 \%$ das respostas.

Algumas vantagens do recurso tecnológico: disponibilidade de conteúdo aos graduandos e profissionais, possibilidade de o aluno realizar simulação; possibilidade de os alunos estudarem nos momentos oportunos; o programa informa ao professor os registros dos exercícios simulados.

Carmen Maria Casquel Monti Juliani Tese de Doutorado, 2003. Departamento de Enfermagem, Faculdade de Medicina de Botucatu $<$ cjuliani@fmb.unesp.br>
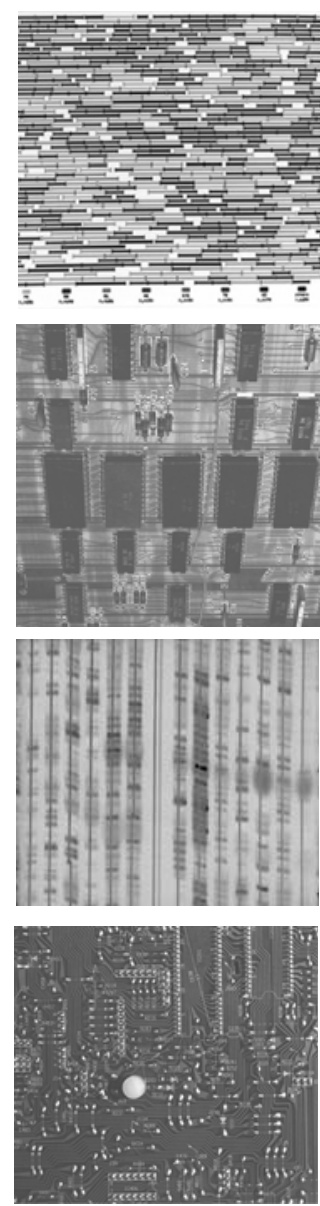

PALAVRAS-CHAVE: Enfermagem; Informática; tecnologia educacional.

KEY WORDS: Nursing; Informatic; educational technology.

PALABRAS CLAVE: Enfermería; Informática; tecnología educativa.

Recebido para publicação em 15/05/03. Aprovado para publicação em 27/05/03. 


\section{Aprendizagem Baseada em Problemas na Faculdade de Medicina de Marília: sensibilizando o olhar para o idoso}

Problem based learning at the Marilia Faculty of Medicine: making people aware of the elderly

O objeto deste estudo foi a formação do médico $e$ a sua sensibilização para lidar com a pessoa idosa. Envolveu a análise dos olhares de estudantes de Medicina e pacientes idosos dentro da proposta de Aprendizagem Baseada em Problemas e do currículo da Faculdade de Medicina de Marília- Famema.

Objetivos: Analisar a percepção de estudantes de Medicina da Famema, formados a partir de currículo apoiado na Aprendizagem Baseada em Problemas - ABP, com ênfase na formação de médicos sensibilizados para a atenção das pessoas idosas; analisar as representações de estudantes e idosos acerca do que é ser um médico sensibilizado para a questão do envelhecimento.

Métodos: Foram coletados dados por meio de um questionário aplicado aos estudantes de Medicina ao final da $4^{\mathrm{a}}$. série, e entrevistas realizadas com pacientes idosos e estudantes ao final da $6^{\mathrm{a}}$. série. Empregou-se a análise temática para a inferência dos dados com a utilização de duas categorias de análise: "o estudante e a aprendizagem sobre o idoso", $e$ "o idoso e o médico para a pessoa idosa". Resultados e discussão: Os olhares dos estudantes sobre sua aprendizagem ao final da $4^{\mathrm{a}}$. e da $6^{\mathrm{a}}$. séries são complementares $e$ coincidentes. Entre as temáticas, encontramse: a abrangência e adequação da 'Unidade 17, sobre Envelhecimento', $e$ sua contribuição no desenvolvimento pessoal, desempenhos $e$ competências para aprender a aprender, saber pensar, resgatar a perda do humano em nossas vidas, e saber cuidar; a doença é mais representada no currículo do Curso de Medicina do que o doente, existindo ilhas curriculares' com uma atuação mais condizente com a atenção às necessidades dos pacientes; a 'disease' prepondera em muito sobre a 'illness'; teoria e prática permanecem pouco integradas; nada substitui a prática $e$ contato direto com a realidade, os problemas de papel, por melhor que sejam construídos $e$ utilizados nas sessões de tutoria, não superam a vivência real, especialmente para o desenvolvimento de competências para saber cuidar; o reconhecimento da importância do resgate do humano na práxis médica nem sempre se manifesta na ação concreta de uma atenção integral à saúde do idoso; há ainda o preconceito em relação ao idoso, ao envelhecimento, à velhice, manifesto na forma da discriminação dessas pessoas nas unidades de saúde: um desafio a ser superado. A expectativa dos pacientes idosos é a de encontrar um médico que compreenda a representação de sua doença, a sua 'illness' na sua condição de vida e que, assim, desenvolva uma relação de esperança e confiança, bases da terapêutica bem sucedida, e do melhor gerenciamento de seus problemas de saúde. $\mathrm{O}$ olhar do idoso para o idoso e do médico para a pessoa idosa tem um componente do olhar especular, com seus reflexos que avivaram novas reflexões sobre o próprio idoso, $e$ também o do olhar o outro, um olhar humano de quem busca auxílio, alívio e compreensão, carinho e cuidado, esperança $e$ cura.

\section{Ricardo Shoiti Komatsu \\ Tese de Doutorado, 2003 Faculdade de Filosofia e Ciências Universidade Estadual Paulista, Marília <komatsu@famema.br>}

PALAVRAS-CHAVE: Aprendizagem Baseada em Problemas; Educação médica; Geriatria; formação. KEY WORDS: Problem Based Learning; Health Education; Geriatry; training professionals. PALABRAS CLAVE: Aprendizaje Basada en Problemas; Educación Medica; Geriatria; formación. 